\title{
Dispositivos curriculares estaduais para a Educação Física (1996-2016): da elaboração à implementação
}

http://dx.doi.org/10.11606/1807-5509202000040653

Resumo

Esta pesquisa tem como objetivo apresentar as características com as quais os currículos estaduais propostos para a Educação Física foram elaborados e implementados. Com abordagem quali-quantitativa, compreende 68 documentos curriculares vinculados às Secretarias Estaduais de Educação, publicados entre 1996 e 2016. A pesquisa dá visibilidade: à procedência territorial e distribuição anual desses materiais, às etapas da educação básica contempladas nesses documentos, às suas temáticas mais recorrentes, suas terminologias, além de aspectos autorais e dos processos de implementação. As análises indicam: a) aumento desses materiais, sobretudo a partir de 2006; b) produção estimulada por marcos legais e documentos ligados ao Ministério da Educação; c) indícios de que a construção desses materiais está relacionada com demarcações políticas; d) autorias marcadas por redes de relações coletivas, destacando-se o diálogo entre equipes de Secretarias, professores da Rede e/ou professores de ensino superior; e) existência de formações continuadas como estratégia de divulgação dos currículos. Ao fornecermos um quantitativo elevado de fontes dentro de uma periodização considerável (21 anos), levantamos questões sobre as produções curriculares, base para futuras análises. A amplitude de dados também evidencia a potencialidade de pesquisas que assumam os documentos curriculares como objetos de estudos.

Palavras-chave: Política educacional; Escola; Documento curricular; Rede estadual.

\section{Introdução}

No campo da Educação Física (EF), observamos um aumento de pesquisas associadas à análise de documentos curriculares (DCs) produzidos por iniciativas estaduais e municipais no território nacional. Esse movimento éfruto de demandas que, em primeira análise, seriam indicadas por marcos legais, como a Lei de Diretrizes e Bases da Educação Nacional ${ }^{1}$ (LDB), que coloca sob responsabilidade das Redes de Educação a construção de seus currículos.

Ao reconhecermos que essa demanda não provém exclusivamente da LDB de 1996, assinalamos também a Lei $n^{\circ}$ 10.172/01 que, ao aprovar o Plano Nacional de Educaçáo ${ }^{2}$ (PNE), sinaliza a necessidade de elaboraçáo de planos estaduais e municipais adequados às especificidades locais e que estejam integrados ao PNE. Além disso, lembramos que, na década de 1960, já existiam normas descentralizadoras e estimuladoras para a construção de currículos estaduais e municipais, como na revisão do primeiro PNE, em 1965ª

Concomitantemente à elaboração desses materiais, destacamos o movimento da produção acadêmica em acompanhar esse processo de construção de documentos orientadores para a prática do professor. Dentre os assuntos abordados por essas pesquisas, há discussóes sobre o conteúdo documental ${ }^{3}$; o modo como os documentos projetam as práticas pedagógicas ${ }^{4}$; o binômino intencionalidade e avaliaçáo ${ }^{5}$; currículo ${ }^{6}$; além de estudos sobre conteúdos como ginástica ${ }^{7}$, 
dança ${ }^{8}$ e esporte ${ }^{9}$.

Essas pesquisas evidenciam o esforço em dar visibilidade e aprofundar os elementos que constituem a prática pedagógica (objetivos, conteúdos, metodologias de ensino e avaliação) e que se fazem presentes nos DCs. Porém, é pertinente uma investigação que proponha um levantamento mais abrangente dessas orientaçóes produzidas pelos Estados, principalmente que amplie o seu quantitativo dentro de uma periodizaçáo considerável, sobretudo que abarque toda a extensão do Brasil. Quando há uma iniciativa nesse sentido, os trabalhos não focalizam somente $\mathrm{a} \mathrm{EF}$ e, quando abordam especificamente esse componente curricular, utilizam apenas os últimos documentos construídos pelos Estados ${ }^{4-6}$ e/ou delimitam as análises em uma ou duas etapas da educação básicaa ${ }^{7-9}$.

Dada a importância do tema na atualidade, interessa-nos, neste estudo, produzir um levantamento dos currículos estaduais produzidos para a Educação Física, publicados no período de 1996 e 2016. Com base nesses dados, assumimos, como objetivo desta pesquisa, apresentar as características com as quais os currículos estaduais foram elaborados e implementados. Nos limites deste artigo, realizamos um mapeamento quantitativo, favorecendo uma leitura com periodização ampla e um número significativo de fontes de diferentes Estados brasileiros. Assim, nosso intuito, com esta pesquisa, também é oferecer dados para que outras

\section{Método}

A pesquisa é de abordagem quali-quantitativa e possui como fontes 68 DCs produzidos pelos 26 Estados e no Distrito Federal. Estabelecemos, como critérios de inclusão, todos os materiais em que o ano de publicação se encontrava entre 1996 e 2016, direcionados à educação básica ${ }^{\mathrm{c}}$. Tomamos como referência o ano de 1996, tendo em vista a promulgação de um dos principais marcos para a escolarização brasileira, a LDB ${ }^{1}$.

O processo de delimitação das fontes ocorreu em três etapas. Na primeira, realizada no segundo semestre de 2015, foram feitas buscas nos portais das Secretarias Estaduais de Educação dos 26 Estados e do Distrito Federal. Ainda nesse mesmo período, como segunda etapa, consultamos as Secretarias por telefone e/ou contato por e-mail. Foram realizadas duas solicitaçôes: a) confirmar a publicação dos DCs obtidos no levantamento; b) perguntar sobre a existência de outros DCs produzidos pelo Estado e solicitar o envio investigações, inclusive de natureza qualititativa, sejam realizadas sobre o objeto. Diante das terminologias assumidas pelos materiais didático-pedagógicos para identificar-se, como "referencial", "diretriz", "parâmetro", "proposta", "plano", houve a necessidade de elaborarmos um conceito que compreendesse suas características. Optamos por esse caminho pois, mesmo que esses documentos possuam concepçôes teóricas diferentes, eles se aproximam por compartilhar de algo comum: orientar a intervenção pedagógica.

A fim de abranger essa variedade de expressóes, analisamos o objeto de maneira ampliada. Desse modo, assumimos as fontes como dispositivos ${ }^{10}$ nos quais o professor busca ferramentas para ensinar e mediar o ensino, constituídos por protocolos que direcionam a leitura e visam a orientar a ação docente. Entendidas assim, as fontes configuram-se também como currículos direcionados aos professores ${ }^{11}$, cujo objetivo é prescrever orientaçôes didático-pedagógicas para suas práticas

Inicialmente, descrevemos o caminho metodológico para a produção do levantamento desses dispositivos, evidenciando o processo de seleção das fontes e organizaçáo dos dados. Em um segundo momento, apresentamos os resultados, analisando-os em diálogo com a literatura. Nas consideraçóes finais, retomamos os principais achados e anunciamos possibilidades de investigaçóes.

desses documentos.

$\mathrm{Na}$ terceira etapa, realizada no início do primeiro semestre de 2016, (re)visitamos os portais das Secretarias e entramos em contato com autores de pesquisas acadêmicas que apresentavam algum tipo de mapeamento de DCs ${ }^{\mathrm{d}}$. Posteriormente, optamos por concluir o processo de levantamento das fontes.

Organizamos o processo de análise dos dados em dois momentos: para investigarmos as características de elaboração, mapeamos os DCs em sua procedência territorial e distribuição anual, as etapas da educação básica contempladas nesses documentos, as suas temáticas mais recorrentes, terminologias, além de aspectos autorais. Para tanto, procedemos à leitura da capa do material, da contracapa, do sumário relacionado com a EF e do texto referente a esse componente curricular. No caso específico dos dados referentes à autoria, identificamos os nomes dos autores responsáveis pelos textos da $\mathrm{EF}$ e, posteriormente, 
pesquisamos o seu vínculo institucional. Quando o documento não apresentava essas informaçóes, realizamos buscas no Currículo Lattes.

Para mapearmos as características de implementação dos DCs, lemos cada documento, sobretudo em sua parte introdutória, buscando elementos sobre o modo como ele foi apresentado aos professores, após a sua elaboração.

\section{Resultados e Discussão}

\section{Procedência territorial e distribuição anual dos dispositivos curriculares}

Quanto à territorialização da produção, todos os Estados e o Distrito Federal elaboraram ao menos um dispositivo, no período entre 1996 e 2016. Foram encontrados 68 documentos nas cinco regióes do Brasil, assim distribuídas: 7 DCs provindos da Região Sul (10,3\%), 14 da Região Sudeste (20,6\%), 13 da Região Norte (19,1\%), 21 da Região Nordeste $(30,9 \%)$ e 13 DCs da Regiāo Centro-Oeste (19,1\%). No QUADRO 1, organizamos a distribuição dos documentos

Quando relacionamos o quantitativo de Estados com o total de materiais, a Região Nordeste é aquela que mais elabora DCs (21). Porém, essa região é também aquela que possui maior quantidade de Estados. Em contrapartida, a Região Sudeste apresenta elevada produção de DCs em termos proporcionais: 3,5 documentos em média por Estado, em um total de 14 . Contribuem para esse número os Estados de São Paulo e Rio de Janeiro, em que foram construídos dez DCs. O Centro-Oeste possui média de 3,25 DCs por Estado, o Sul e o Nordeste 2,3 DCs, e o Norte 1,8 DCs por Estado. Com base nesses dados, sistematizamos a FIGURA 1, no qual encontramos a distribuição anual dos DCs. Ele foi elaborado de acordo com os DCs construídos até 2014, conforme FIGURA 1.

Ao levarmos em consideração que, em um período de 12 anos, foram produzidos oito DCs, ou seja, entre 1996 e 2007, sinalizamos o ano de 2008 como aquele que demarca um acréscimo na produção de documentos (7 DCs). A FIGURA 1 evidencia também que em 2009 (14 DCs) e 2013 (15 DCs) há maior número de publicaçóes.

$\mathrm{O}$ processo de análise dos materiais evidenciou que a publicação e a atualização dos documentos, a partir de 1998, ocorrem em decorrência das demandas de leis, conforme encontramos em 69\% dos materiais analisados. Além disso, essas iniciativas possuem relação com a busca pela melhoria do ensino na Rede, a (re) orientação dos professores com base nas especificidades dos componentes curriculares, além da influência das avaliações externas.

Dentre as legislações que fundamentam os DCs, a LDB (Lei no. 9394/96) ${ }^{1}$ se constitui como o marco legal mais referenciado pelos currículos, pois foi mencionada em documentos de 17 Estados (AL, AM AP, DF, GO, MA, MG, MS, MT, PB, PI, SC, SE, SP, RJ, RO, $\mathrm{RS})$. Essa representatividade pode estar relacionada com o que afirma o Art.12 da $\mathrm{LDB}^{1}$, ao suscitar um novo momento nas políticas educacionais, em que é atribuída aos estabelecimentos de ensino a incumbência de elaborar e executar as suas propostas pedagógicas .

Além de a LDB se configurar como referência para a construção dos documentos, os Parâmetros Curriculares Nacionais da Educação Física ${ }^{12}$ (PCNs) aparecem em DCs de 14 Estados (AC, AL, AM, AP, DF, ES, MA, MG, MS, PB, PE, RJ, RO, SE). $\mathrm{O}$ processo de análise das fontes evidenciou que os PCNs, de forma diferente do marco oficial antes citado, se constituem como um guia para os DCs. Eles contribuem para uniformizar os currículos por meio de seus conteúdos mínimos, sinalizando critérios para a sua seleção e organização ao longo dos anos. Além disso, o documento também acena para os objetivos atribuídos à Educação Física nos diferentes ciclos da escolaridade.

A partir de 2006, há também relação com outros textos ligados ao Ministério da Educação (MEC), que indicam estimular e/ou serem parâmetros na produção de currículos pelos Estados. Dentre eles, há as Orientaçóes Educacionais Complementares aos Parâmetros Curriculares Nacionais $(\mathrm{PCN}+)^{13}$, Diretrizes Curriculares Nacionais para o Ensino Fundamental ${ }^{14}$ e Matrizes de Referência dos exames nacionais e estaduais, como o Exame Nacional do Ensino Médio ${ }^{15}$ e o Sistema de Avaliação da Educação Básica ${ }^{16}$.

Mesmo diante do crescente número de DCs, há períodos em que esse quantitativo reduz, como nos anos de 2011 e 2014 . Nesse caso, há a possibilidade de que novos documentos estivessem em fase de elaboração, (re)formulação ou 
nenhuma das alternativas. Todavia, é interessante analisar até que ponto esse descréscimo é fruto de maior ou menor investimento em políticas curriculares do Estado. No caso de menor investimento ou até mesmo ausência, é possível que haja uma descontinuidade de orientação nos processos sucessórios de governo, ou descontinuidade política, como afirmam VenÂncio e Bettit ${ }^{17}$.

Ao focalizarmos a continuidade e/ou descontinuidade de açóes ligadas ao âmbito educacional, levamos em consideração os movimentos políticos de Estado ou de Governo ${ }^{\text {e }}$. Em nossos achados, há uma elevada produção de DCs acompanhada das alternâncias de governantes nos Estados. Essa análise foi possível pela aproximação dos dados referentes ao ano de produção dos documentos com as mudanças de governos.

Esse cenário também é apresentado na pesquisa realizada pelo Centro de Estudos e Pesquisas em Educação, Cultura e Ação Comunitária ${ }^{19}$ (Cenpec), que analisou 23 currículos produzidos para os anos finais do ensino fundamental em 16 Estados (AC, AL, BA, DF, GO, MA, MT, MS, PR, PE, PI, RJ, RS, RO, SP e SE). O relatório final desenvolvido pela instituição sinaliza que há um movimento de renovação/elaboraçẫo dos documentos pelos Estados e pelo Distrito
Federal, de acordo com as alteraçôes de governo.

Diante desse panorama, cabe-nos perguntar: essas produções levaram em consideração aquilo que foi proposto nos DCs anteriores? Nesse caso, 23 DCs produzidos por 13 Estados (AL, AM, AP, CE, ES, MA, MT, PB, RJ, RO, RS, SE, SP) afirmam não prosseguir com o que foi elaborado em materiais anteriormente propostos. Há, nesse processo, indícios de uma ação intencional que visa à demarcação de uma política de governo desassociada de uma política de Estado. Desse modo, sinalizamos a importância de futuras investigações que deem visibilidade ao modo como as mudanças de governo possuem relaçáo com as políticas educacionais de Estado, sobretudo para a elaboração dos DCs.

Já no ano de 2015 e início de 2016, não identificamos documentos finalizados, apenas versões preliminares ou em fase de elaboração. Uma possibilidade interpretativa para a ausência de publicaçôes de DCs nesse período referese ao que sinaliza a Base Nacional Comum Curricular (BNCC)20.Como uma das finalidades do documento é "[...] orientar os sistemas na elaboração de suas propostas curriculares, [...]"20:24, é possível que o motivo de tal "atraso" esteja relacionado com a necessidade de adequaçáo dos Estados em frente às novas exigências dessa Base.

QUADRO 1 - Procedência territorial e anual dos DCs.

\begin{tabular}{|c|c|c|}
\hline Regiăo / Estado & Ano & Título do documento \\
\hline \multicolumn{3}{|l|}{ Centro-Oeste } \\
\hline Distrito Federal (DF) & $\begin{array}{l}2009 \\
2013 a \\
2013 b \\
2013 c \\
2013 d\end{array}$ & $\begin{array}{l}\text { Orientaçôes curriculares, ed. básica: ensino médio } \\
\text { Currículo em movimento da ed. básica: ed. infantil } \\
\text { Currículo em movimento da ed. básica: ensino fundamental I } \\
\text { Currículo em movimento da ed. básica: ensino fundamental II } \\
\text { Currículo em movimento da educação básica: ensino médio }\end{array}$ \\
\hline Goiás (GO) & $\begin{array}{l}2009 a \\
2009 b \\
2009 c \\
2013 a \\
2013 b\end{array}$ & $\begin{array}{l}\text { Reorientação curricular do } 1^{\circ} \text { ao } 9^{\circ} \text { ano: matrizes curriculares } \\
\text { Reorientaçáo curricular do } 1^{\circ} \text { ao } 9^{\circ} \text { ano: sequências didáticas } \\
\text { Matrizes curriculares e sequências didáticas: artes e EF } \\
\text { Currículo referência de educação física para o fundamental } \\
\text { Currículo referência de educação física para o ensino médio }\end{array}$ \\
\hline Mato Grosso (MT) & 2010 & Orientações curriculares: área de Linguagens \\
\hline Mato Grosso do Sul (MS) & $\begin{array}{l}2012 \mathrm{a} \\
2012 \mathrm{~b}\end{array}$ & $\begin{array}{l}\text { Referencial curricular da rede estadual: ensino fundamental } \\
\text { Referencial curricular da rede estadual: ensino médio }\end{array}$ \\
\hline
\end{tabular}




\begin{tabular}{|c|c|c|}
\hline Regiáo / Estado & Ano & Título do documento \\
\hline \multicolumn{3}{|l|}{ Nordeste } \\
\hline Alagoas (AL) & $\begin{array}{l}2010 \\
2014 a \\
2014 b\end{array}$ & $\begin{array}{l}\text { Documento norteador para intervenção pedagógica da EF } \\
\text { Referencial curricular da ed. básica da rede estadual } \\
\text { Referencial curricular da rede estadual: Linguagens }\end{array}$ \\
\hline Bahia (BA) & 2013 & Subsídios didáticos para o trabalho pedagógico no ensino fund. \\
\hline Ceará (CE) & $\begin{array}{l}2008 \\
2009 \\
2011\end{array}$ & $\begin{array}{l}\text { Metodologias de apoio: áreas de ling., cód. e suas tecnologias } \\
\text { Metodologias de apoio: matrizes curriculares para ensino médio } \\
\text { Orientaçōes curriculares para a educação infantil }\end{array}$ \\
\hline Maranhão (MA) & $\begin{array}{l}2009 \\
2010 \\
2014\end{array}$ & $\begin{array}{l}\text { Referencial curricular da EF: } 1^{\circ} \text { ao } 9^{\circ} \text { ano: ensino fundamental } \\
\text { Referencial curricular do ensino fund.: } 1^{\text {a }} \text { a } 4^{\mathrm{a}} \text { série } / 1^{\circ} \text { ao } 5^{\circ} \text { ano } \\
\text { Diretrizes curriculares }\end{array}$ \\
\hline Paraíba (PB) & 2010 & Referenciais curriculares do ensino fundamental \\
\hline Pernambuco (PE) & $\begin{array}{l}2010 \\
2013 a \\
2013 b \\
2013 c \\
2014\end{array}$ & $\begin{array}{l}\text { Orientaçóes teórico-metodológicas: ensino fund. e médio } \\
\text { Parâmetros na sala de aula: EF - ensino fundamental e médio } \\
\text { Conteúdos de educação física por bimestre para o ensino fund. } \\
\text { Conteúdos de educação física por bimestre para o ensino médio } \\
\text { Parâmetros de formação docente: línguas, arte e EF }\end{array}$ \\
\hline Piauí (PI) & $\begin{array}{l}2013 a \\
2013 b\end{array}$ & $\begin{array}{l}\text { Diretrizes curriculares: Caderno } 1 \\
\text { Diretrizes curriculares: Caderno } 2\end{array}$ \\
\hline Rio Grande do Norte (RN) & 2009 & Proposta de componentes curriculares para o ensino médio \\
\hline Sergipe (SE) & $\begin{array}{l}2007 \\
2012\end{array}$ & $\begin{array}{l}\text { Proposta curricular de educaçáo física } \\
\text { Referencial curricular: rede estadual de ensino de Sergipe }\end{array}$ \\
\hline \multicolumn{3}{|l|}{ Norte } \\
\hline Acre $(\mathrm{AC})$ & $\begin{array}{l}2009 \\
2010 a \\
2010 b\end{array}$ & $\begin{array}{l}\text { Cadernos de orientaçáo curricular: ciclo inicial: caderno } 1 \\
\text { Orientaçôes curriculares para o ensino fund.: caderno } 1 \\
\text { Orientaçōes curriculares para o ensino médio: caderno } 1\end{array}$ \\
\hline Amapá (AP) & 2009 & Plano curricular para a educação básica do Estado do Amapá \\
\hline Amazonas (AM) & $\begin{array}{l}2008 \mathrm{a} \\
2008 \mathrm{~b} \\
2008 \mathrm{c} \\
2012\end{array}$ & $\begin{array}{l}\text { Proposta curricular do ensino fundamental do } 1^{\circ}, 2^{\circ} \text { e } 3^{\circ} \text { ano } \\
\text { Proposta curricular do ensino fundamental do } 4^{\circ} \text { e } 5^{\circ} \text { ano } \\
\text { Proposta curricular do ensino fundamental do } 6^{\circ} \text { ao } 9^{\circ} \text { ano } \\
\text { Proposta curricular de educaçáo física para o ensino médio }\end{array}$ \\
\hline Pará (PA) & 2003 & Proposta curricular para o ensino médio \\
\hline Rondônia (RO) & $\begin{array}{l}2013 a \\
2013 b\end{array}$ & $\begin{array}{l}\text { Referencial curricular de Rondônia: ensino fundamental } \\
\text { Referencial curricular de Rondônia: ensino médio }\end{array}$ \\
\hline Roraima (RR) & 2012 & Referencial curricular estadual para o ensino médio \\
\hline Tocantins (TO) & 2009 & Referencial curricular do ensino fundamental \\
\hline \multicolumn{3}{|l|}{ Sudeste } \\
\hline Espírito Santo (ES) & $\begin{array}{l}2009 a \\
2009 b \\
2009 c\end{array}$ & $\begin{array}{l}\text { Currículo básico da escola estadual: ensino fundamental I } \\
\text { Currículo básico da escola estadual: ensino fundamental II } \\
\text { Currículo básico da escola estadual: ensino médio }\end{array}$ \\
\hline Minas Gerais (MG) & 2008 & Proposta curricular de educação física: fundamental e médio \\
\hline
\end{tabular}




\begin{tabular}{|c|c|c|}
\hline Regiáo / Estado & Ano & Título do documento \\
\hline Rio de Janeiro (RJ) & $\begin{array}{l}2006 \mathrm{a} \\
2006 \mathrm{~b} \\
2010 \mathrm{a} \\
2010 \mathrm{~b} \\
2012 \\
2013\end{array}$ & $\begin{array}{l}\text { Reorientação curricular: linguagens e códigos } \\
\text { Reorientaçáo curricular: educação física/materiais didáticos } \\
\text { Proposta curricular: um novo formato: educaçáo física } \\
\text { Diretrizes curriculares para o ensino fundamental: anos iniciais } \\
\text { Currículo mínimo 2012: educação física } \\
\text { Currículo mínimo 2013: curso normal/formação de professores }\end{array}$ \\
\hline São Paulo (SP) & $\begin{array}{l}2008 \\
2011 \\
2012 \\
2014\end{array}$ & $\begin{array}{l}\text { Proposta curricular do Estado de São Paulo: educação física } \\
\text { Currículo do Estado de São Paulo: ling., cód. e suas tecnologias } \\
\text { Currículo do Estado de São Paulo: ling., cód. e suas tecnologias } \\
\text { Orientaçóes curriculares da EF nos anos iniciais do ensino fund. }\end{array}$ \\
\hline Sul & & \\
\hline Paraná (PR) & $\begin{array}{l}2006 \\
2008\end{array}$ & $\begin{array}{l}\text { Educação física: ensino médio } \\
\text { Diretrizes curriculares da educação básica: educação física }\end{array}$ \\
\hline Rio Grande do Sul (RS) & 2009 & Liçōes do Rio Grande: linguagens, códigos e suas tecnologias \\
\hline Santa Catarina (SC) & $\begin{array}{l}1998 \\
2000 \\
2001 \\
2014\end{array}$ & $\begin{array}{l}\text { Proposta curricular de Santa Catarina } \\
\text { Diretrizes para a organizaçáo da prática escolar } \\
\text { Diretrizes 3: organizaçáo da prática escolar na educação básica } \\
\text { Proposta curricular de Santa Catarina: formação integral }\end{array}$ \\
\hline
\end{tabular}

FIGURA 1- Distribuição anual dos DCs.

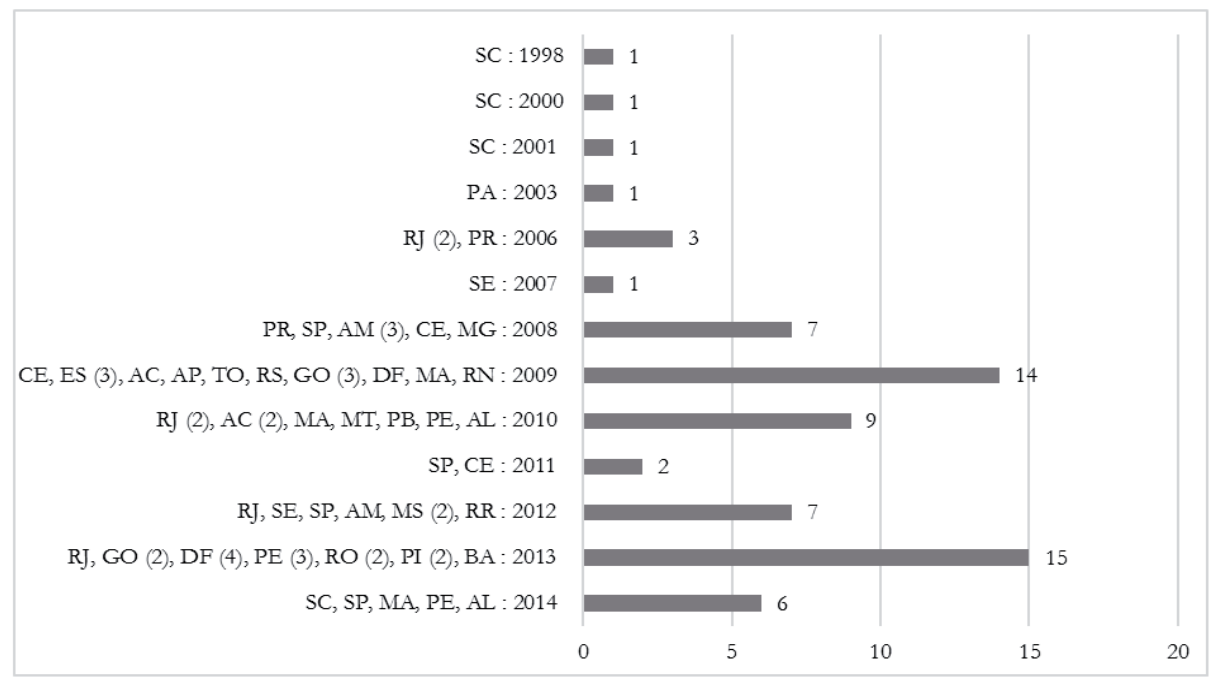

\section{Os dispositivos curriculares e as etapas da educação básica}

O mapeamento das etapas da educação básica contempladas nos DCs acena para um maior número de proposiçốes para o ensino fundamental e médio, ao mesmo tempo em que há uma carência em relação à educação infantil.

Com o objetivo de dar visibilidade a essa distribuição, elaboramos a TABELA 1. Nela, organizamos os documentos produzidos de acordo com as suas regióes, Estados, etapas da educação básica e anos de publicaçáo. Quando os documentos elaborados em determinado ano atenderam a mais de uma etapa da educaçáo básica, 
indicamos na tabela uma mesma referência para o ano de publicação, é o caso de Santa Catarina. No ano de 1998, o Estado elaborou um documento que abrangeu a educação infantil, os anos iniciais e finais do ensino fundamental e do ensino médio.

Nas situaçóes em que um Estado publicou documentos distintos no mesmo ano, eles foram apresentados com uma especificação ao lado do ano referenciado, como acontece no
Distrito Federal. A Secretaria de Educação do DF publicou quatro documentos específicos para cada etapa da educação básica, a saber: educação infantil (2013a), anos iniciais do ensino fundamental (2013b), anos finais do ensino fundamental (2013c) e ensino médio (2013d). É preciso considerar que 23 materiais atendem a mais de uma etapa da educação básica, conforme visualizamos abaixo:

TABELA 1 - Distribuição dos DCs por etapas da educação básica.

\begin{tabular}{|c|c|c|c|c|c|}
\hline & Regiáo/Estado & Ed. Infantil & $\begin{array}{l}\text { Ens. Fundamental } \\
\text { (anos iniciais) }\end{array}$ & $\begin{array}{l}\text { Ens. Fundamental } \\
\text { (anos finais) }\end{array}$ & Ens. Médio \\
\hline \multirow{3}{*}{ Centro-Oeste } & Distrito Federal & $2013 a$ & $2013 b$ & $2013 c$ & $2009,2013 \mathrm{~d}$ \\
\hline & Goiás & & 2009a, 2009c & $\begin{array}{l}\text { 2009a, 2009b, 2009c, } \\
2013 \mathrm{a}\end{array}$ & $2013 b$ \\
\hline & Mato Grosso & & 2010 & 2010 & 2010 \\
\hline \multirow{7}{*}{ Nordeste } & Alagoas & 2010, 2014a & $2010,2014 b$ & $2010,2014 b$ & $2010,2014 b$ \\
\hline & Bahia & & 2013 & 2013 & \\
\hline & Ceará & 2011 & & & 2008,2009 \\
\hline & Pernambuco & & $2010,2013 a$ & 2010, 2013a, 2013b, 2014 & $2010,2013 b, 2013 c$ \\
\hline & Piauí & & $2013 a$ & $2013 a$ & $2013 b$ \\
\hline & Rio Grande do Norte & & & & 2009 \\
\hline & Sergipe & & 2007,2012 & 2007,2012 & 2007,2012 \\
\hline \multirow{3}{*}{ Norte } & Acre & & 2009 & $2010 \mathrm{a}$ & $2010 b$ \\
\hline & Amapá & & 2009 & 2009 & 2009 \\
\hline & Tocantins & & 2009 & 2009 & \\
\hline \multirow{4}{*}{ Sudeste } & Espírito Santo & & $2009 a$ & $2009 b$ & $2009 c$ \\
\hline & Minas Gerais & & & 2008 & 2008 \\
\hline & Rio de Janeiro & & $2010 b$ & 2006a, 2006b, 2010a, 2012 & $\begin{array}{l}\text { 2006a, 2006b, 2010, } \\
2012\end{array}$ \\
\hline & São Paulo & & 2014 & 2008, 2011, 2012 & $2008,2011,2012$ \\
\hline \multirow{3}{*}{ Sul } & Paraná & & & 2008 & 2006,2008 \\
\hline & Santa Catarina & & & 2009 & 2009 \\
\hline & Rio Grande do Sul & 1998,2014 & $1998,2000,2001,2014$ & $1998,2000,2001,2014$ & $\begin{array}{l}\text { 1998, 2000, 2001, } \\
2014\end{array}$ \\
\hline Total - $68(100 \%)$ & & $6(9 \%)$ & $30(44 \%)$ & $41(60 \%)$ & $40(59 \%)$ \\
\hline
\end{tabular}


O primeiro documento destinado à orientaçáo da prática pedagógica de professores da educação infantil foi elaborado em SC, no ano de 1998. Outro DC que dialoga com essa etapa foi produzido em 2010, por AL. Encontramos ainda quatro materiais construídos pelos Estados de $\mathrm{CE}^{21}$, $\mathrm{DF}^{22}, \mathrm{AL}^{23}$ e $\mathrm{SC}^{24}$. Ou seja, de 68 DCs, essa etapa inicial da educação básica aparece em seis documentos (9\%).

Dentre os fatores que configuram a educação infantil como a etapa de ensino em que há o menor quantitativo de DCs elaborados, podemos mencionar a municipalização do ensino nos Estados, orientada pela $\mathrm{LDB}^{\mathrm{f}}$. Nesse documento, há indicação de novos procedimentos na gestão e financiamento da educação municipal, possibilitando aos municípios a criação de seu próprio sistema de ensino, sobretudo voltado à educação infantil e ao ensino fundamental. Sobre isso, a LDB, em seu art. 11, descreve que cabe aos municípios

Oferecer a educação infantil em creches e pré-escolas, $\mathrm{e}$, com prioridade, o ensino fundamental, permitida a atuação em outros níveis de ensino somente quando estiverem atendidas plenamente as necessidades de sua área de competência e com recursos acima dos percentuais mínimos vinculados pela constituição federal à manutençấo e desenvolvimento do ensino ${ }^{1: 6}$.

Em relação ao ensino fundamental, há a seguinte distribuição: 30 DCs contemplam os anos iniciais (44\%), produzidos por 20 Estados; e 41 DCs os anos finais $(60 \%)$, construídos por 24 Estados. Como última etapa da educação básica, o ensino médio esteve presente em 40 DCs (59\%). Quando comparado com outras etapas de ensino, o ensino médio foi aquele em que houve maior número de participação dos Estados na elaboração de documentos (23 Estados e o DF), não estando presente em DCs da BA, PB, TO.

Diante desse levantamento, perguntamo-nos: A EF estaria presente em todos os dispositivos? Como a EF está apresentada nos documentos, se levarmos em consideração as etapas da educação básica?

Dos 68 DCs analisados, não foram encontradas orientações para o ensino da EF em seis documentos: $\mathrm{CE}^{21}, \mathrm{DF}^{22}, \mathrm{AL}^{23}, \mathrm{MA}^{26}, \mathrm{PA}^{27}, \mathrm{RN}^{28}$. Dos $62 \mathrm{DCs}$ em que há proposiçóes para a $\mathrm{EF}$, três contemplam a educação infantil (4,4\%), com ausência da EF em $\mathrm{CE}^{21}$, $\mathrm{DF}^{22}$ e $\mathrm{AL}^{23} ; 39$ estão voltados para o ensino médio $(57,3 \%)$, já que esse componente curricular não foi apresentado no documento do $\mathrm{RN}^{28}$; 30 DCs para os anos iniciais do ensino fundamental (44,1\%); e 40 DCs para os anos finais $(58,8 \%)$, pois o documento de $\mathrm{MA}^{26}$ não abordou a EF em seu currículo.

\section{A recorrência das temáticas abordadas nos dispositivos para a Educação Física}

Ao mapearmos as temáticas abordadas nos textos da EF, foi necessário inicialmente apresentar o modo como os DCs foram escritos, isto é, se eles foram desenvolvidos inteiramente para a EF ou se englobaram outros componentes curriculares em seu interior.

A TABELA 2 acena para duas possibilidades de elaboração dos DCs: a) contendo discussōes para/ sobre a EF em documento específico; b) englobando em seu interior outros componentes curriculares ${ }^{\mathrm{g}}$. A referida tabela pode ser visualizada abaixo.

Do total de 62 DCs, encontramos 20 DCs desenvolvidos exclusivamente para a $\mathrm{EF}(32,2 \%)$ e $42 \mathrm{DCs}$ que, além da EF, produziram textos para outros componentes curriculares $(67,8 \%)$. Com base na leitura dos textos relacionados com a EF e seus respectivos sumários presentes em 62 DCs, identificamos as temáticas mais abordadas, como sinalizado no FIGURA 2:

$\mathrm{Na}$ FIGURA 2, além da apresentação dos temas abordados, mantivemos a organização sobre os modos como os DCs foram elaborados: se compreenderam outros componentes curriculares ou se foram exclusivos para a Educação Física. Dentre os temas mais discutidos nos DCs, demos visibilidade àqueles que apareceram em no mínimo dez DCs, somados entre os dispositivos que englobam os demais componentes curriculares e dispositivos exclusivos para a EF.

A FIGURA 2 apresenta os dados em ordem decrescente: os fundamentos teóricos (41 DCs) e orientaçóes metodológicas (32 DCs) foram as temáticas mais recorrentes, seguidas dos conteúdos de ensino da EF (23 DCs). Por fim, identificamos os temas interdisciplinares (16 DCs) - educação em valores, inclusão, temas transversais, educação do campo, temática indígena, direitos humanos, educação ambiental, educação étnico-racial e diversidade sexual - além dos temas relacionados com a história da EF (15 DCs) e avaliação (14 DCs).

Dentre os DCs, há 21 documentos que não trazem em seu corpo os fundamentos teóricos e/ou metodológicos, deixando de oferecer sustentação no processo de construçáo dos seus conteúdos. Esse mesmo cenário foi discutido pelo Cenpec ${ }^{19: 78}$, ao afirmar que "[...] em algumas disciplinas, o aporte teórico dos conteúdos é frágil ou desconhecido [...]”. Os dados desta 
pesquisa envidenciam a anecessidade de os DCs apresentarem, para o professor, a abordagem teórica assumida no documento e quais seriam os aspectos metodológicos que poderiam orientar as escolhas do docente em relação à organização curricular e aos objetivos desse componente curricular.

Sobre os conteúdos de ensino da EF, 23 DCs discutem aquilo que pode ser ensinado nas aulas, focalizando principalmente os seus aspectos conceituais e históricos. A maior recorrência em abordar o conteúdo de ensino relaciona-se com a natureza desses DCs, os quais se dedicam a apresentar elementos que oferecem um repertório de informaçóes e de referenciais de cunho mais teórico para o professor. A leitura detalhada desses 23 DCs acena para quatro que possuem características prescritivas ${ }^{29-32}$. Nesse caso, além desses documentos apresentarem "o que ensinar", produzem também alternativas de "como ensinar".

Em análise dos DCs que abordam os temas interdisciplinares, notamos orientaçóes fundamentadas na necessidade de contemplar a diversidade cultural existente no país. Esses DCs foram influenciados sobretudo pela LDB e pelas Diretrizes Curriculares Nacionais ${ }^{14}$, que asseguram nos currículos, além de uma base nacional comum, uma parte diversificada "[...] exigida pelas características regionais e locais da sociedade, da cultura, [...]"'. Os temas também se referem à necessidade de diálogo entre os componentes curriculares. Por meio deles, e respeitando as especificidades dos diferentes campos do conhecimento, os conteúdos podem ser organizados de modo a ampliar e a aprofundar os processos de ensino e de aprendizagem, produzindo problematizaçóes sobre temas concretos presentes no cotidiano dos alunos ${ }^{14}$.

Já em relação à história da EF, há características que aproximam esses DCs, em especial: a) a visão da $\mathrm{EF}$ como área de conhecimento que, historicamente, sempre entrou em conflitos em relação às delimitaçóes do seu campo de intervenção; b) a crítica ao caráter esportivista/ tecnicista das aulas, principalmente nas décadas de 1960 e 1970; e c) o discurso da busca pela legitimidade no contexto escolar a partir da década de 1980.

Por fim, dentre os 42 DCs em que estão presentes tanto a EF como outros componentes curriculares, cinco operam uma apropriação do que foi apresentado como diretriz de avaliação para outros componentes curriculares, no texto da EF - pensando em suas especificidades. Por outro lado, nos materiais produzidos somente para a EF, há um número mais elevado de orientaçóes em relação à avaliação (9 DCs). Nesse caso, os DCs levantam críticas a uma avaliação com viés classificatório, marcada pela aprovação ou reprovação do aluno. De modo geral, os documentos ressaltam a importância de a avaliação assumir uma natureza formativa,

[...] cuja vivência é marcada pela lógica da inclusão, do diálogo, da construção da autonomia, da mediação, da participação, da construção da responsabilidade com o coletivo, objetivando a consolidação de uma rede de saberes durante todo o processo pedagógico ${ }^{(33: 116)}$.

Há ainda a proposição de uma avaliação mais progressista, que é "[...] diagnóstica, dinâmica, coletiva, reflexiva, dialógica, com o foco no aluno, no professor e no processo de ensino/ aprendizagem" $32: 49$.

Diante desses dados, indagamos: quais seriam as implicaçóes em analisarmos o modo como os documentos são elaborados em articulação com os temas abordados? Observamos que os documentos produzidos para/sobre a EF de forma específica apresentam maior diversidade de temáticas, quando comparados com aqueles que contemplam outros componentes curriculares. Dentre as seis temáticas presentes no gráfico, apenas a que se refere aos conteúdos de ensino da EF possui maior expressividade numérica nos documentos que se aproxima dos outros componentes curriculares. 
TABELA 2 - As formas como os documentos se apresentam.

\begin{tabular}{|c|c|c|c|c|c|}
\hline \multirow{2}{*}{ Características } & \multicolumn{5}{|c|}{ Regióes e dispositivos curriculares } \\
\hline & Centro-Oeste & Nordeste & Norte & Sudeste & Sul \\
\hline $\begin{array}{l}\text { Documentos exclusivos } \\
\text { para a EF }(32,2 \%)\end{array}$ & $\begin{array}{l}\text { GO (2009b) } \\
\text { GO (2013a) } \\
\text { GO (2013b) }\end{array}$ & $\begin{array}{l}\text { AL (2010) } \\
\text { MA (2009) } \\
\text { PE (2010) } \\
\text { PE (2013a) } \\
\text { PE (2013b) } \\
\text { PE (2013c) } \\
\text { SE (2007) }\end{array}$ & $\begin{array}{l}\text { AC (2010a) } \\
\text { AC (2010b) } \\
\text { AM (2012) }\end{array}$ & $\begin{array}{l}\text { MG (2008) } \\
\text { RJ (2006b) } \\
\text { RJ (2010a) } \\
\text { RJ (2012) } \\
\text { RJ (2013) }\end{array}$ & $\begin{array}{l}\text { PR (2006) } \\
\text { PR (2008) }\end{array}$ \\
\hline $\begin{array}{l}\text { Documentos } \\
\text { englobando outras } \\
\text { disciplinas }(67,8 \%)\end{array}$ & $\begin{array}{l}\text { DF (2009) } \\
\text { DF (2013b) } \\
\text { DF (2013c) } \\
\text { DF (2013d) } \\
\text { GO (2009a) } \\
\text { GO (2009c) } \\
\text { MS (2012a) } \\
\text { MS (2012b) } \\
\text { MT (2010) }\end{array}$ & $\begin{array}{l}\text { AL (2014b) } \\
\text { BA (2013) } \\
\text { CE (2008) } \\
\text { CE (2009) } \\
\text { MA (2014) } \\
\text { PI (2013a) } \\
\text { PI (2013b) } \\
\text { PE (2014) } \\
\text { SE (2012) }\end{array}$ & $\begin{array}{l}\text { AC (2009) } \\
\text { AM (2008a) } \\
\text { AM (2008b) } \\
\text { AM (2008c) } \\
\text { AM (2012) } \\
\text { AP (2009) } \\
\text { RO (2013a) } \\
\text { RO (2013b) } \\
\text { RR (2012) } \\
\text { TO (2009) }\end{array}$ & $\begin{array}{l}\text { ES (2009a) } \\
\text { ES (2009b) } \\
\text { ES (2009c) } \\
\text { RJ (2006a) } \\
\text { RJ (2010b) } \\
\text { SP (2008) } \\
\text { SP (2011) } \\
\text { SP (2012) } \\
\text { SP (2014) }\end{array}$ & $\begin{array}{l}\text { RS (2009) } \\
\text { SC (1998) } \\
\text { SC (2000) } \\
\text { SC (2001) } \\
\text { SC (2014) }\end{array}$ \\
\hline
\end{tabular}

FIGURA 2 - Temáticas mais abordados nos dispositivos curriculares.

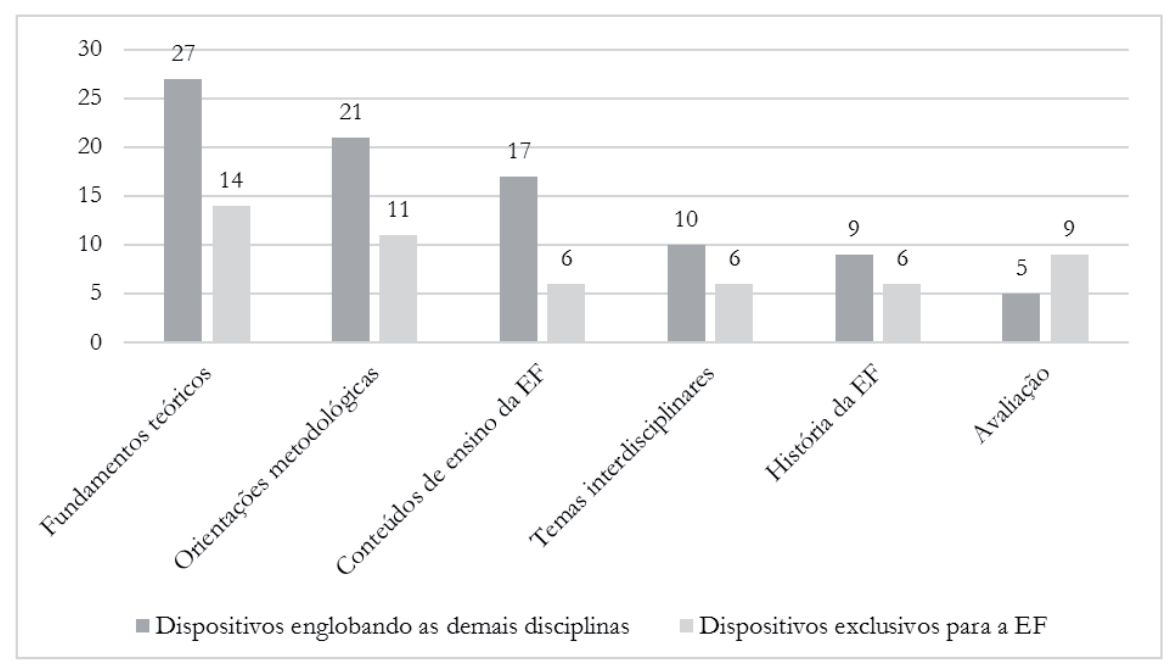

662 • Rev Bras Educ Fís Esporte, (São Paulo) 2020 Out-Dez;34(4):653-72 
As terminologias dos dispositivos
curriculares

Embora tenhamos assumido um conceito que contemple as finalidades dos diferentes DCs, faz-se pertinente dar visibilidade às terminologias/títulos apresentadas(os) por eles. Assim, identificamos 23 formas de nomear os referidos documentos.
Com o objetivo de organizar essas terminologias, assumimos como referência três critérios: a) aqueles que trazem o termo "currículo" no título do material; b) aqueles que não possuem o termo "currículo" e que apresentam uma nomenclatura particular de um determinado Estado; e c) aquele que se identifica como "Livro didático". A FIGURA 3 apresenta essas categorias:

FIGURA 3 - Nomenclaturas identificadas a partir do título dos dispositivos.

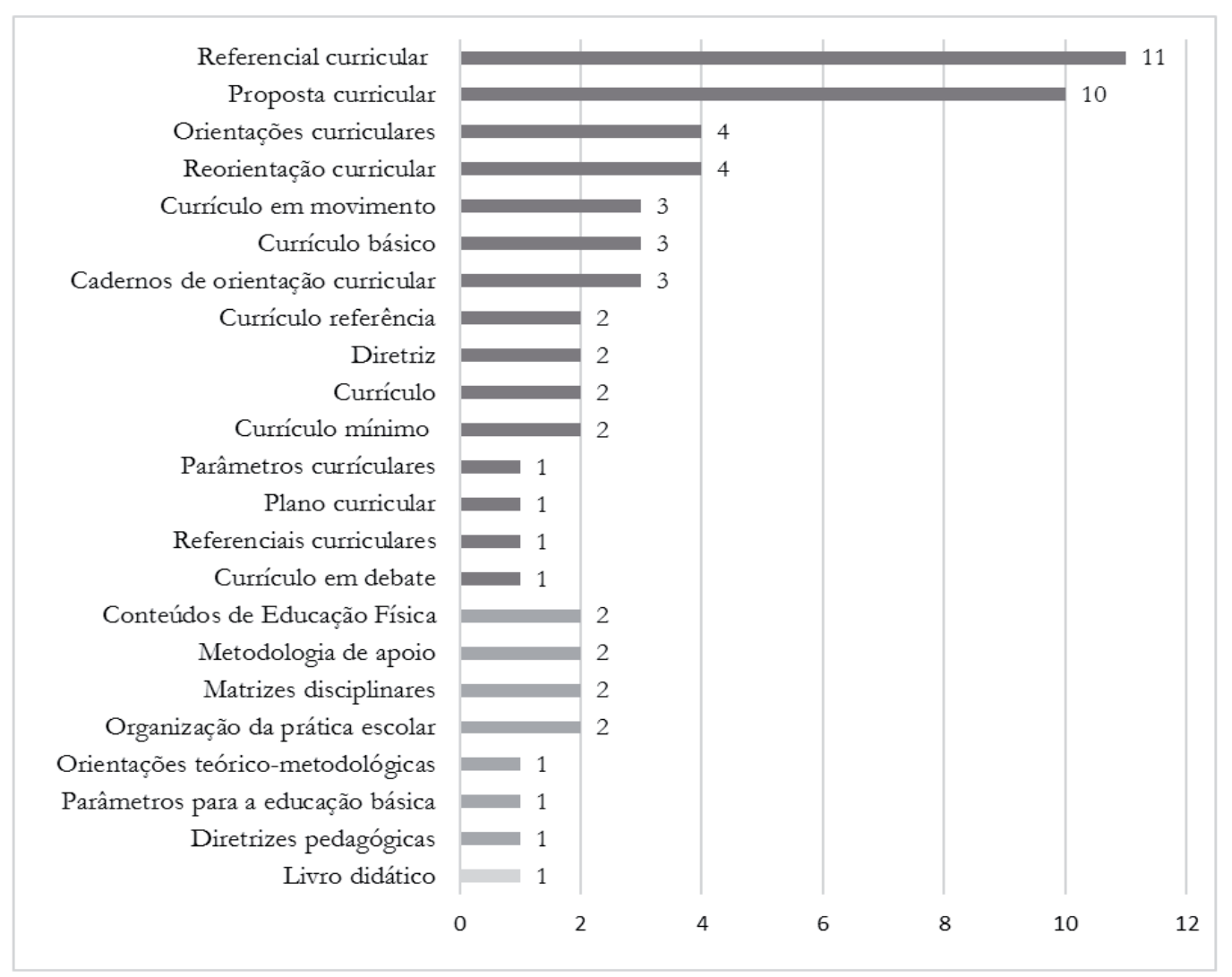


Os dados acenam para a alta recorrência do termo "currículo" nos títulos, aparecendo em 15 das 23 terminologias identificadas. Diante desse primeiro agrupamento, os termos "referencial curricular" e "proposta curricular" são os que se destacam quantitativamente. Contudo, com base nas leituras realizadas nos documentos, não encontramos uma justificativa para a utilização desses nomes, o que também não ocorreu em relação aos DCs agrupados na segunda categoria. Os materiais que apresentam, em seus títulos, uma terminologia associada a determinado Estado, apenas sugerem seu propósito: apresentar "conteúdos para a Educação Física", servir como uma "metodologia de apoio" ao docente e propor uma "organização da prática escolar".

Assim, mesmo que esses documentos não justifiquem a escolha dos seus títulos, muitos assumiram que eles não poderiam ser vistos como uma "receita" ou algo "pronto" para os professores, mas iriam propor um rol de conteúdos mínimos, que serviria de apoio para eles. Esses indícios nos ajudaram a compreender terminologias como "currículo básico" e "currículo mínimo", por exemplo. Nesse caso, ao serem assumidos como material de suporte básico/mínimo e como um parâmetro/orientaçáo, esses DCs não limitam o trabalho docente, pois deixam espaço para que os professores planejem suas aulas.

Diante desse cenário, perguntamos: a que remeteria o nome "currículo em debate"? Foi escolhido para evidenciar que determinado DC foi debatido por um grupo de colaboradores? E o termo "currículo em movimento"? Expressaria algo que está em construção, sujeito a alteraçōes? $\mathrm{E}$ as demais nomenclaturas?

Para respondermos a essas questōes, foi necessário estabelecermos relação entre as terminologias utilizadas pelos DCs com as referências assumidas para a sua elaboração. É o caso do documento do Distrito Federal ${ }^{22}$, que faz referência a Gimeno Sacristán ${ }^{11}$ para mostrar como o currículo em movimento deve ser constantemente ressignificado e avaliado. Nesse sentido, Gimeno Sacristán ${ }^{11}$ ressalta a visão dinâmica do currículo como um processo que se realiza em diferentes âmbitos de decisões e realizações.

A heterogeneidade de terminologias evidencia as intencionalidades dos DCs em criar uma identidade para aquele Estado, instituição, ou grupo de pesquisa que ajudou em sua elaboração. Esses achados se aproximam do debate proposto por SAMPaIO ${ }^{34}$, ao afirmar que "[...] não se pode apreciar o referencial das orientaçóes em si, mas na relaçáo com as condiçóes dos grupos que dele se apropriaram e com o processo em que ocorreu a elaboração de suas propostas".

Outra possibilidade de interpretarmos a variedade de nomenclaturas se encontra no relatório final para currículos do ensino fundamental do Cenpec ${ }^{19}$.

\footnotetext{
Vê-se, assim, que essa diversidade não pode ser interpretada apenas como fruto da autonomia dos entes federados: ela se relaciona não somente com o fato de o país ser uma república federativa, mas, também, com a falta de consenso quanto ao significado dos próprios termos educacionais. O recurso a tantas palavras estreitamente relacionadas sugere que questôes de sentido e de significado perpassam o campo dos estudos do currículo, possivelmente gerando, em cada estado, uma significação própria e diversa da adotada nos demais.
}

Dentre outras nomenclaturas utilizadas para a identificação dos DCs, há "livro didático" (LD), identificado em $\mathrm{PR}^{35}$. Nesse Estado, o LD é reconhecido como material direcionado aos alunos, voltado para os seus processos de aprendizagem e com característica mais propositiva de atividades, quando comparado com os demais materiais curriculares.

Nesse contexto, temos assumido um conceito ampliado de LD, em que esse tipo de material é "[...] produzido com a intenção de orientar o ensino do professor e a aprendizagem dos alunos, estando relacionados com o planejamento, intervenção e avaliação" "4:44. O aluno, ao utilizar esse dispositivo, pode aprender pela apropriaçáo de um saber cuja existência é materializada nele. No espaço escolar, o LD seria “[...] lugar de realizações inventivas, as que tratam do 'como fazer' e que acompanham as reformas vindas de cima ou as inovaçôes do campo"10.

Embora um documento tenha assumido essa terminologia, as discussóes em torno do "Livro didático" como objeto de estudo se apresentam de maneira crescente no campo científico da EF. De acordo com Bolzan e Santos ${ }^{4}$, esse aumento de interesse tem ocorrido sobretudo a partir do ano 2000, quando há pesquisas que investigam a produção e discussão de materiais dessa natureza. Dentre elas, Rufino e Darido ${ }^{36}$ e Rodrigues e DARIDo ${ }^{37}$, que analisam os LDs com base na opinião de alunos e professores, após a sua "aplicaçáo" nas escolas; ANGULSKi et al..$^{38}$, que se debruçaram ao Livro didático público do Paraná. 
Contudo, é preciso destacar que, mesmo com a recente preocupação da área em debater o tema, não encontramos livros didáticos para a $\mathrm{EF}$ no Plano Nacional do Livro Didático (PNLD).

Sinalizamos também outras iniciativas que se caracterizam como LDs, dentre elas, as obras Para ensinar educação física: possibilidades de intervenção na escola ${ }^{39}$ e os Cadernos do professor de São Paulo ${ }^{29}$. Também identificamos a aprovação de um livro ${ }^{40}$ que compôs o acervo do professor pelo Programa Nacional Biblioteca da Escola, criado pelo Ministério da Educação ${ }^{\mathrm{h}}$.

\section{A procedência autoral dos dispositivos: do vínculo institucional às relações de parceria}

Foram mapeados 140 autores que participaram da elaboração de 50 DCs. Em 12 DCs não foi possível a identificação de autoria, pois não houve a apresentação nominal daqueles que colaboraram com a sua materialização.

Há autores provenientes de equipes de Secretarias da Educação (técnico-pedagógicos, gerentes de departamento de desporto, coordenadores, membro de equipe curricular), professores da rede estadual, professores de ensino superior (estadual, federal e/ou particular, assessoria técnica e professores de institutos federais ${ }^{i}$. Com o objetivo de apresentar o modo como os DCs foram elaborados, especificamente no que se refere à composição de autoria, apresentamos a TABELA 3.

A produção coletiva é expressa pelo número de pessoas envolvidas na elaboração dos DCs, mas sobretudo pela participação de autores que atuam em diferentes instâncias, principalmente nas Secretarias, nas Redes Estaduais e no ensino superior. Além de as Secretarias Estaduais de Educação buscarem a colaboração dos professores que atuam na educação básica, elas também têm estabelecido parcerias com universidades federais, estaduais e particulares, além de empresas privadas, com o objetivo de que eles assessorem a produção dos DCs. Galian ${ }^{41: 658}$, ao analisar os processos de construção desses materiais, afirma que

[...] houve avanço no que se refere à busca pela participaçáo dos agentes da escola no debate sobre o currículo. Outro aspecto que representa mudança é a chamada à cena de outros elementos para compor as equipes de elaboração das propostas: as empresas especializadas. Por outro lado, como permanência,

TABELA 3 - Dispositivos curriculares e as procedências autorais.

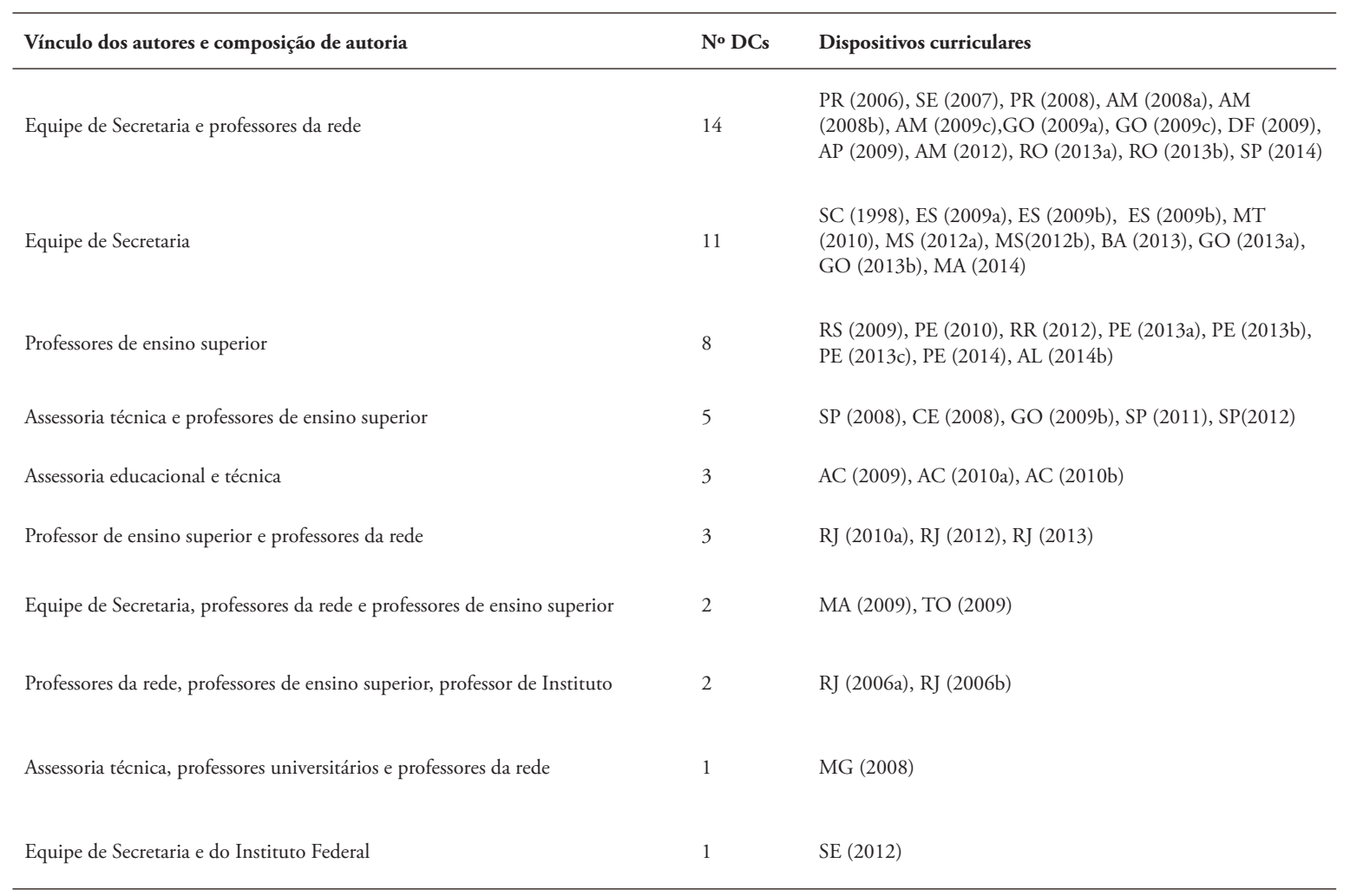


destaca-se a manutenção do espaço das universidades nesse debate, por meio do estabelecimento de assessorias por parte dos seus docentes/pesquisadores.

Os dados desta pesquisa também evidenciam que as mudanças na forma de compor a autoria estão relacionadas com as mudanças de gestáo em um mesmo Estado. É o caso dos DCs produzidos por MA, RJ, SE e SP, em que a conjuntura de produção se modifica, quando comparada com o DCs elaborados anteriormente. Há Estados (GO e CE) em que um dispositivo produzido teve a autoria de professores da rede, juntamente com membros da equipe de Secretaria, porém, em outra oportunidade, no processo de elaboração de um novo currículo, essa configuração se modifica. No caso, outro grupo de autores, oriundo de assessoria técnica, participou como colaboradores em parceira com professores de ensino superior.

Na produçáo dos 50 DCs, além de encontrarmos a participação de autores vinculados às Secretarias e escolas da Rede Estadual, foram reconhecidas 13 instituiçóes de ensino superior federal, 9 de ensino superior particular, 8 consultores educacionais e 7 instituiçóes de ensino superior estadual. Dentre as instituiçóes de ensino, 37\% estão na Regiáo Sudeste, $24,3 \%$ estão na Região Nordeste, $18,9 \%$ na Região Sul, $10,8 \%$ na Região Centro-Oeste e $8,1 \%$ na Região Norte.

Ao mapearmos as relaçóes entre Secretarias, instituiçôes, empresas e universidades na elaboração dos DCs, é relevante destacar que elas buscam dar legitimidade ao que está sendo pensado e materializado para a área. No entanto, esse movimento de parceria, sobretudo com empresas privadas, é passível de críticas.

\section{Implementação dos dispositivos via formação continuada}

Além do movimento de parceria com professores na elaboração dos DCs, também analisamos o seu processo de implementação. Como os DCs objetivam nortear o trabalho didático-pedagógico do professor na escola, cabe-nos perceber as açôes que potencializam a aproximaçáo do corpo docente com esses materiais.

Dentre as iniciativas, assumimos a formação continuada como um movimento que fortalece e materializa essa aproximação. Uma análise detalhada sobre esses processos se faz relevante, pois a participação dos professores na construção dos DCs pode qualificá-los e legitimá-los. Produzidos dessa maneira, os DCs podem constituir-se em uma
"[...] estratégia de divulgação e convencimento do professorado sobre determinado projeto, proposta pedagógica ou lei sobre a educação"42:58.

Dos 62 DCs, 21 sinalizam a formação continuada como espaço em que foram elaborados os currículos estaduais. Essas iniciativas foram registradas nos DCs de nove Estados (AC, ES, GO, MG, PE, PR, RJ, RS, SP). Na Regiâo Norte, o Estado do Acre foi aquele em que a formaçáo dos professores se configurou como possibilidade de construção dos DCs referentes aos anos de 2009 e 2010. Nesse mesmo período, o Instituto Abapuru de Educação e Cultura foi o responsável pelo desenvolvimento dos referidos DCs.

$\mathrm{Na}$ Regiāo Centro-Oeste, a Secretaria Estadual de Educação de Goiás iniciou, em 2004, um programa de formaçáo continuada denominado "Reorientação curricular". No ano de 2007, esse programa foi retomado pelo projeto "Coordenação de Ensino Fundamental Itinerante".O primeiro documento de Goiás nos mostra que as formaçóes ocorreram por meio de oficinas pedagógicas por áreas de conhecimento, seminários e encontros de formação. As equipes escolares, em cada município do Estado, organizaram grupos de estudos e enviaram suas experiências para compor o DC.

Com relação à Regiâo Nordeste, os documentos do Estado de $\mathrm{PE}^{33}, \mathrm{PE}^{43}$ e $\mathrm{PE}^{44}$ foram aqueles produzidos no âmbito das formaçóes continuadas. Elas ocorreram em parceria com o Programa de Formação Continuada da Escola de Educação Física (ESEF-UPE), Grupo de Pesquisa e Estudos Etnográficos em Educação Física e Esportes (ETHNÓS) e o Colégio de Aplicação, todos pertencentes à Universidade Federal de Pernambuco. Esse processo ocorreu por meio do "Projeto Professor-Autor", em que foi organizado um acervo de material de apoio para as aulas do ensino fundamental e médio, com o objetivo de enriquecer as práticas pedagógicas.

$\mathrm{Na}$ Região Sul, a formação continuada ocorreu no Paraná, por meio do "Projeto Folhas", em 2006. No ano de 2008, o Departamento de Educação Básica Itinerante ofereceu para os professores da Rede Estadual 16 horas de formação continuada. O seu objetivo era discutir os fundamentos teóricos das diretrizes, mas também os aspectos metodológicos de sua implementação em sala de aula.

$\mathrm{Na}$ Regiáo Sudeste, os quatro Estados acenaram para a formaçáo continuada como um espaço de elaboração de seus documentos. Minas Gerais 
incluiu curso de formação dos docentes, por meio de um sistema de apoio denominado "Centro de Referência Virtual do Professor (CRV)". O Espírito Santo propôs um "Guia de Implementação do Novo Currículo", incluindo formaçáo continuada para os professores, a fim de incorporar novas sugestóes ao currículo.

No Rio de Janeiro, mapeamos a parceria estabelecida entre a Secretaria Estadual de Educação e a Universidade Federal do Rio de Janeiro, em que foi promovido um curso para professores de diferentes componentes curriculares para construção do documento de 2006. Nesse processo, os docentes foram incentivados a elaborar planos de aula e realizá-los em seu cotidiano, de maneira que interagissem com a proposta curricular, naquele momento. Por fim, em São Paulo, a formação continuada realizada pela Secretaria Estadual de Educação foi denominada "Orientaçóes Técnicas". Ela atendeu a diversas diretorias de ensino, compostas pelos professores coordenadores do núcleo pedagógico de cada área. Essas formaçóes produziram os documentos de 2008, 2011 e 2012.

Diante do apresentado, os dados indicaram diferenças em relação ao modo como as formaçôes foram realizadas: há investimentos em formaçôes on-line; formaçóes dirigidas por grupos de pesquisas das universidades e por grupos "referência" pertencentes às Secretarias; formaçóes por região e por empresas que prestam assessoria.

\section{Considerações finais}

A pesquisa possui como objetivo apresentar as características com as quais 68 currículos estaduais propostos para a Educação Física foram elaborados e implementados. Os dados do trabalho evidenciam aumento na elaboração desses materiais, especialmente a partir da segunda metade da década de 2000.

Ressaltamos o quanto a produção coletiva se fez presente, sobretudo na relação entre equipes de Secretarias com professores da Rede e/ou professores de ensino superior. Destacamos ainda a presença de assessorias educacionais vinculadas a instituiçóes e/ou empresas prestadoras de serviços para construção de currículos.

Os dados também evidenciam o aumento de investimento em políticas públicas na produção
Sobre os DCs em que não identificamos a formaçáo continuada como espaço para a sua elaboração, é necessário ponderar que, além da possível falta de iniciativa por parte das autoridades ligadas à educação, a desigualdade entre os Estados, no processo de construção e implementação, pode ser fruto das lacunas em relação ao suporte técnico e estrutural das Secretarias. Nesse sentido,

\footnotetext{
Há os casos em que se têm equipes grandes e consolidadas há tempos; e há aqueles em que os técnicos são poucos e trabalham em situações mais precárias. Nas visitas aos estados e ao Distrito Federal, percebeu-se uma variedade muito grande nas condiçôes instaladas nas secretarias para que os processos de elaboração e implementação curricular ocorram. Isso faz com que alguns estados tenham possibilidades muito menores de que suas políticas curriculares de fato alcancem as escolas e que elas recebam o apoio necessário nessa temática $^{19: 228}$.
}

Se, por um lado, observamos que as formaçóes continuadas são estratégicas em relação à elaboração dos documentos pois, por meio delas, é possível articular as intencionalidades do currículo com as possibilidades de intervençóes, por outro, existem críticas em relação à implementação dos materiais. As principais referem-se à não preparação dos professores para trabalhar com o que é proposto ${ }^{19}$, embora tenhamos clareza das apropriaçóes dos professores entre o currículo prescrito e o praticado ${ }^{11}$.

desse tipo de material que, além de justificado e incentivado por marcos legais e documentos vinculados ao Ministério da Educação, é acompanhado de outros interesses. Dentre eles, a adequaçáo a demandas provindas de avaliaçóes externas e as demarcaçóes políticas, tendo em vista as indicaçóes de continuidades e descontinuidades de políticas de governo na elaboraçáo dos documentos.

A análise dos dispositivos nos mostra tensôes em relação às políticas de governo e às políticas de Estado. Reconhecemos que muitas medidas precisam ser tomadas para que políticas educativas sejam de fato assumidas como prioridade e se tornem políticas de Estado. Pensá-las dessa maneira é um caminho profícuo, pois as descontinuidades 
de políticas públicas oneram o Estado, além de dificultar o trabalho do professor e a formação dos alunos.

Sinalizamos ainda que as mudanças de governo têm provocado limitaçóes no acesso aos documentos curriculares, sobretudo aqueles construídos em administraçóes anteriores, que não possuem a mesma forma de gerir o Estado. Nesse sentido, açōes que favoreçam uma transparência e melhor acesso do que foi produzido em outros momentos seriam necessárias, tendo em vista a preservação da memória histórica dos currículos.

Esse contexto evidencia a necessidade de estudos futuros que se dediquem a realizar uma investigação in loco, aproximando-se das Secretarias Estaduais. Em diálogo com os secretários e demais gestores, o foco das discussões seria as políticas de governo e de Estado sobre os processos de produçáo de currículos.

As iniciativas das Secretarias Estaduais de Educação em construir esses materiais em parceria com os professores da Educação Básica também precisam ser consideradas como possibilidade de pesquisa, haja vista que se sabe pouco sobre como os educadores se relacionam com as propostas curriculares $^{45}$. Nesse caso, não se justificaria a produção de um material sem açóes que favoreçam seu uso. No presente estudo, a realizaçáo de formaçóes continuadas se materializa de diferentes formas: por meio do universo on-line, ou de maneira presencial. Caberia, posteriormente, a análise de como o(s) autor(es) se envolveram com a construção dos DCs, desde a sua produção, via formação continuada, até o processo de aceitação dos materiais por parte dos docentes.

Sobre questôes envolvendo a EF, observamos que os DCs apresentam uma abordagem mais teórica do seu conteúdo, havendo poucas iniciativas que se aproximam das prescrições didáticas (proposições de atividades a serem desenvolvidas nas aulas, ou o "como fazer").

Além disso, há menor presença/discussão de temas interdisciplinares e sobre a avaliação, o que também evidencia a necessidade de futuros estudos que aprofundem a análise dessas temáticas presentes nos DCs. Outrossim, caberiam investigaçóes que compreendam a ausência da EF em alguns documentos e analisem os interesses do governo ao propor parcerias com os professores da Rede, professores do ensino superior e/ou assessorias técnicas na elaboração de DCs.

Ressaltamos que os DCs, como objetos de estudos, demonstram ser um campo vasto para investigação no campo do currículo. Antes, porém, tão importante como adentrar nos estudos desse campo, seria produzir um mapeamento expressivo desses materiais, sinalizando as características relacionadas com a sua produção e implementação. Dessa maneira, fornecer, concomitantemente, um quantitativo elevado de fontes dentro de uma periodizaçáo considerável (21 anos) foi um movimento válido para levantar questóes sobre as produçóes curriculares, tornando-se base para futuras análises.

\section{Notas}

a. O primeiro PNE surgiu em 1962, elaborado já na vigência da primeira Lei de Diretrizes e Bases da Educação Nacional, Lei no 4.024, de 1961. Em 1965, sofreu uma revisão, quando foram introduzidas normas descentralizadoras e estimuladoras da elaboraçáo de planos estaduais ${ }^{2}$.

b. Consideramos o currículo como um processo de construção social, resultado das diversas operaçóes às quais é submetido, escolha dos conteúdos, métodos, objetivos e avaliação nos diversos níveis de ensino, bem como nos diferentes tempos/espaços escolares ${ }^{11}$.

c. Dos 68 documentos, apenas o de Mato Grosso do Sul é impresso e foi enviado pela Coordenadoria de Políticas para Educação Básica, da Secretaria de Educação desse Estado.

d. Diante do contato via e-mail com autores, obtivemos retorno da professora Luciana Pereira Machado Ribeiro, que nos enviou o documento do Estado do Pará.

e. Segundo Oliveira ${ }^{18: 329}$, políticas de governo “[...] são aquelas em que o Executivo decide num processo de implementação de medidas e programas, visando a responder às demandas da agenda política interna. Já as políticas de Estado são aquelas que envolvem mais de uma agência do Estado, passando, em geral, pelo Parlamento ou por instâncias diversas de discussão, resultando em mudanças de outras normas ou disposiçóes preexistentes, com incidência em setores mais amplos da sociedade."

f. A municipalização se faz presente desde a época imperial nas discussóes políticas e nos atos legais, culminando na criação dos sistemas públicos de ensino no Brasil, na esfera municipal, com a promulgação da Constituição Federal de 
a. O primeiro PNE surgiu em 1962, elaborado já na vigência da primeira Lei de Diretrizes e Bases da Educação Nacional, Lei no 4.024, de 1961. Em 1965, sofreu uma revisão, quando foram introduzidas normas descentralizadoras e estimuladoras da elaboração de planos estaduais².

b. Consideramos o currículo como um processo de construção social, resultado das diversas operações às quais é submetido, escolha dos conteúdos, métodos, objetivos e avaliação nos diversos níveis de ensino, bem como nos diferentes tempos/espaços escolares ${ }^{11}$.

c. Dos 68 documentos, apenas o de Mato Grosso do Sul é impresso e foi enviado pela Coordenadoria de Políticas para Educação Básica, da Secretaria de Educação desse Estado.

d. Diante do contato via e-mail com autores, obtivemos retorno da professora Luciana Pereira Machado Ribeiro, que nos enviou o documento do Estado do Pará.

e. Segundo Oliveira ${ }^{18: 329}$, políticas de governo “[...] são aquelas em que o Executivo decide num processo de implementação de medidas e programas, visando a responder às demandas da agenda política interna. Já as políticas de Estado são aquelas que envolvem mais de uma agência do Estado, passando, em geral, pelo Parlamento ou por instâncias diversas de discussão, resultando em mudanças de outras normas ou disposiçóes preexistentes, com incidência em setores mais amplos da sociedade."

f. A municipalização se faz presente desde a época imperial nas discussóes políticas e nos atos legais, culminando na criação dos sistemas públicos de ensino no Brasil, na esfera municipal, com a promulgação da Constituição Federal de 1988. Esta instituiu os municípios como entes da Federação, portanto, como entes jurídicos com responsabilidades próprias e com liberdade para a criação dos sistemas municipais de ensino ${ }^{25}$.

g. Vale destacar que, em Estados como SP e RS, há documentos ${ }^{29-31}$ apresentando abordagem da EF com outras disciplinas, porém, ao mesmo tempo, produziram materiais exclusivos para cada componente curricular em formato de "Caderno do professor". Nesse caso, consideramos para esta análise apenas o documento-base que deu origem aos Cadernos.

h. Antes intitulado Liçóes do Rio Grande: linguagens, códigos e suas tecnologias ${ }^{32}$, passou a ser chamado no acervo de Afazeres da Educação Física na escola: planejar, ensinar, partilhar ${ }^{40}$.

i. A "assessoria técnica” seria empresas e/ou órgãos educacionais, por exemplo, o Cenpec para o Estado de Goiás em 2009 e o Instituto Abaporu de Educação e Cultura no Acre, em 2009. Algumas parcerias com professores de ensino superior se configuram como assessoria, porém, aqui, não utilizamos essa terminologia para sujeitos vinculados às universidades. Nos institutos, observamos um autor do Instituto Federal de Ciência e Tecnologia da Bahia presente no Sergipe em 2012 e outro do Instituto Nacional de Educaçáo de Surdos (Ines) no Rio de Janeiro nos dois DCs de 2006.

\section{Agradecimentos}

Os autores agradecem às seguintes agências de fomento, pelo auxílio financeiro destinado à pesquisa: Fundação de Amparo à Pesquisa e Inovação do Espírito Santo ( Edital 006/2014, número do processo 67643825, Termo de Outorga 0541/2015); Coordenação de Aperfeiçoamento de Pessoal de Nível Superior (bolsa de Doutorado); Conselho Nacional de Desenvolvimento Científico e Tecnológico (bolsa de produtividade em pesquisa - nível 2 - Educação).

\section{Conflito de interesse}

Não há conflito de interesse. 


\begin{abstract}
State curriculum devices for physical education (1996-2016): preparation to implementation.
\end{abstract}

This study aims to present the characteristics that the curricula State proposal for Physical Education were elaborated and implemented. It uses a qualitative and quantitative approach, reaching 68 documents linked to the State Secretariats of Education, produced between 1996 and 2016. The study gives visibility: the territorial origin and the annual distribution of these materials, the stages of basic education contemplated in these documents, their most recurrent themes, their terminologies, besides the authorship aspects and the implementation processes. Analyses indicate: a) increase of these materials, especially from 2006; b) development stimulated by legal marks and documents linked to the Ministry of Education; c) indications of curricular elaborations related to political demarcation; d) the authorships marked by a collective production, highlighting the relationship between Secretariats teams with Network teachers and / or higher education teachers; e) the existence of continuing education as a strategy to disseminate the curriculum. We emphasize that the curriculum documents as objects of study, demonstrate to be a vast field for curriculum research. At the same time, by providing a high quantity of sources within a considerable periodization (21 years), we raise questions about the curriculum productions, becoming the basis for further analysis. The breadth of data also highlights the potential of research that takes curricular documents as objects of study.

KEYwords: Educational policy; School; Curricular document; State network.

\title{
Referências
}

1. Brasil. Lei no 9394, de 20 de dezembro de 1996. Estabelece as Diretrizes e Bases da Educação Nacional. Diário Oficial da União. 23 dez 1996.

2. Brasil. Lei no 10.172 de 9 de janeiro de 2001. Aprova o Plano Nacional de Educação. Diário Oficial da União. 10 jan 2001.

3. Martiny LE, Florêncio SQN, Gomes-da-Silva PN. O referencial curricular do Rio Grande do Sul: uma análise qualitativa do conteúdo. Pensar a Prática. 2011;14(1):1-14.

4. Bolzan E, Santos W. Propostas didático-pedagógicas e suas projeções para o ensino da educação física. Rev Educ Fis UEM. 2015;26(1):43-57.

5. Tenório KMR, Bezerra BB, Melo MST, et al. Propostas curriculares estaduais para educação física: uma análise do binômio intencionalidade-avaliação. Motriz. 2012;18(3):542-556.

6. Eto J, Neira MG. Reflexôes sobre as Propostas Curriculares de Educação Física do Município de São Paulo e dos Estados de Santa Catarina e Rio de Janeiro. Rev Iberoamericana de Educación. 2014;1:1-11.

7. Carvalho AO, Darido SC, Impolcetto FM. Análise do conteúdo de ginástica nos currículos estaduais brasileiros. Arquivos em Movimento. 2015;11:54-73.

8. Diniz IKS, Darido SC. Análise do conteúdo dança nas propostas curriculares estaduais de educação física do Brasil. Rev Educ Fís UEM. 2015;26(3):353-365.

9. Maldonado DT, Silva SAPS, Neira, MG. O trabalho pedagógico com os esportes coletivos nas propostas curriculares brasileiras para o ensino médio. Rev Bras Educ Fís Escolar. 2015;2(1):61-73

10. Chartier AM. Um dispositivo sem autor: cadernos e fichários na escola primária. Rev Bras Hist Educ. 2002;3:9-26.

11. Sacristán G. O currículo: uma reflexão sobre a prática. Porto Alegre: ArtMed; 2000.

12. Brasil. Secretaria de Educação Fundamental. Parâmetros curriculares nacionais: Educação Física. Brasília: Ministério da Educação; 1998.

13. Brasil. Ministério da Educação. PCN + Ensino Médio: orientaçóes educacionais complementares aos Parâmetros Curriculares Nacionais. linguagens, códigos e suas tecnologias. Brasília: MEC/SEMTEC; 2002.

14. Brasil. Parecer do Conselho Nacional de Educação n. 11, de 7 de julho de 2010, para dispor sobre as Diretrizes Curriculares Nacionais para o Ensino Fundamental de 9 anos. Diário Oficial da União. 9 dez 2010.

15. Brasil. Ministério da Educação. Instituto Nacional de Estudos e Pesquisas Educacionais Anísio Teixeira. Matriz 
de Referência para o ENEM. Brasília: MEC/INEP; 2009

16. Brasil. Ministério da Educação. Plano de Desenvolvimento da Educação: Prova Brasil. Ensino Fundamental: matrizes de referência, tópicos e descritores. Brasília: MEC/INEP; 2008.

17. Venâncio, L.; Betti, M. A proposta curricular de EF do Estado de São Paulo (Brasil): reflexôes e problematizaçôes sobre um processo em andamento. In: Actas do 9. Colóquio sobre questôes curriculares e 5. Colóquio luso-brasileiro; 21-23 jun 2010. p. 2531-2542. Porto: Universidade do Minho; 2010. [acesso em 15 jan 2016]. Disponível em: http://www.fpce.up.pt/coloquio2010/.

18. Oliveira DA. Das políticas de governo à política de Estado: reflexóes sobre a atual agenda educacional brasileira. Educ Soc. 2011;32(115):323-337.

19. Centro de Estudos e Pesquisas em Educação, Cultura e Ação Comunitária. Relatório final: Currículos para os anos finais do ensino fundamental: concepçóes, modos de implantação e usos. São Paulo: Cenpec; 2015.

20. Brasil. Ministério da Educação. Base nacional comum curricular. Brasília: MEC, 2015. [acesso em jan 2016]. Disponível em: http://basenacionalcomum.mec.gov.br/documento/BNCC-APRESENTACAO.pdf

21. Ceará (Estado). Secretaria de Educação. Orientações curriculares para a educação infantil. Fortaleza: SEDUC; 2011.

22. Distrito federal (Estado). Secretaria de Estado de Educação. Currículo em movimento da educação básica: Educação Infantil. Brasília: SEE; $2013 \mathrm{a}$.

23. Alagoas (Estado). Secretaria de Estado da Educação e do Esporte. Referencial curricular da educação básica da rede estadual de ensino de Alagoas. Maceió: SEDUC; 2014 a.

24. Santa catarina (Estado). Secretaria de Estado da Educação. Proposta curricular de Santa Catarina: formação integral na educação básica. Florianópolis: SEE; 2014.

25. Araújo GC, organizador. Política e organização da educação básica. Vitória: GM; 2011.

26. Maranhão (Estado). Secretaria de Estado da Educação. Referencial curricular do ensino fundamental: $1^{\text {a a }} 4^{\mathrm{a}}$ série/1ํ ao $5^{\circ}$ ano. São Luís: SEDUC; 2010.

27. Pará (Estado). Governo do Estado do Pará. Proposta curricular para o ensino médio. Belém: SEDUC; 2003.

28. Rio Grande do Norte (Estado). Secretaria da Educação e da Cultura. Proposta de componentes curriculares para o ensino médio. Natal: SEEC; 2009.

29. São Paulo (Estado). Secretaria de Estado da Educação. Proposta Curricular: Caderno do Professor - Educação Física. São Paulo: SEE/IMESP; 2008.

30. São Paulo (Estado) Secretaria da Educação. Currículo do Estado de São Paulo: linguagens, códigos e suas tecnologias. 2. ed. São Paulo: SEE; 2011.

31. São paulo (Estado) Secretaria da Educação. Currículo do Estado de São Paulo: linguagens, códigos e suas tecnologias. 2. ed. São Paulo: SEE; 2012.

32. Rio Grande do Sul (Estado). Secretaria de Estado da Educação. Liçóes do Rio Grande: linguagens, códigos e suas tecnologias. artes e educação física. Porto Alegre: SEDUC; 2009.

33. Pernambuco (Estado). Secretaria de Educação. Orientaçôes teórico-metodológicas: ensino fundamental e médio/ educação física. Recife: SEE; 2010.

34. Sampaio, M. M. F. Propostas curriculares de Estados e Municípios brasileiros para o ensino fundamental e médio. In: Anais do 1. Seminário Nacional: currículo em movimento - perspectivas atuais; 2010. Belo Horizonte, BR. Belo Horizonte: MEC/SEB; 2010. [acesso em 22 jan 2016]. Disponível em:

http://portal.mec.gov.br/programacurriculo-em-movimento-sp-1312968422/relatorios?id=16110.

35. Paraná (Estado). Secretaria de Estado da Educação. Educação física - ensino médio. 2. ed. Curitiba: SEED; 2006. 36. Rufino LGB, Darido SC. Livro didático e tema transversal saúde: o que dizem os alunos. In: Anais do 17. Congresso Brasileiro de Ciências do Esporte e 4. Congresso Internacional de Ciências do Esporte; 11-16 set 2011 ; Porto Alegre, BR. Porto Alegre: CBCE; 2011. p.1-12. [acesso em 22 jan. 2016.]. Disponível em: http:/www. rbceonline.org.br/congressos/index.php/XVII_CONBRACE/2011/index.

37. Rodrigues HA, Darido SC. O livro didático da educação física escolar na visão dos professores. Motriz. 2011;17(1)48-61.

38. Angulski CM, Fugikawa CSL, Santos FA, Gonçalves FS, Navarro RT. Livro didático público de educação física: um diálogo com a prática pedagógica. Anais do 15. Congresso brasileiro de ciências do esporte e 2. Congresso Internacional de Ciências do Esporte. [CD-ROM]; 16-21 set 2007; Recife, BR. Recife: CBCE; 2007.

39. Darido SC, Souza Júnior OM. Para ensinar educação física: possibilidades de intervenção na escola. Campinas: 
Papirus, 2007.

40. González FJ, Fraga AB. Afazeres da educação física na escola: planejar, ensinar, partilhar. Erechim: Edelbra; 2012.

41. Galian CVA. Os PCN e a elaboração de propostas curriculares no brasil. Cadernos de pesquisa. 2014;44(153):648669.

42. Ferreira neto A, Schneider O, Santos W, Ventorim S. Fórmula editorial e graduação: 15 anos de Motrivivência. Motrivivência. 2003;(20-21):57-90.

43. Pernambuco (Estado). Secretaria de Educação. Parâmetros na sala de aula: educação física - ensino fundamental e médio. Recife: SEE; 2013a.

44. Pernambuco (Estado). Secretaria de Educação. Parâmetros de formação docente: línguas, arte e educação física. Recife: SEE; 2014.

45. Gatti BA, Barretto ESS, André MEDA, organizadores. Políticas docentes no Brasil: um estado da arte. Brasília: Unesco; 2011. 